\title{
The Establishment of a TVET (Technical and Vocational Education and Training) College in Kabul in Afghanistan
}

\author{
Duncan Williamson \\ Independent Teacher, Trainer, Author, Consultant, United Kingdom
}

\begin{abstract}
This paper is a case study of how a World Bank Sponsored project in Kabul in Afghanistan introduced to the country a wide range of innovative approaches to teaching and learning. This case study shows how deeply ingrained educational practices and philosophies had to be appreciated and then overcome. One of the key milestones of the project was that it was required to secure the accreditation of a European (in our case Finnish) University in terms of the structure and quality of the curriculum, in terms of its teaching and learning practices, teaching materials and assessment practices and systems. The project spanned the period August 2009 to July 2011; and the case study illustrates the steps taken to convert Afghan students into International standard students at an appropriate level. The students, on average, spoke no English on arrival at the college but within their time in Kabul, they learned sufficient English to cope with our innovative methods, as well as learning to read, write, speak and be assessed in English. By the end of our time in Kabul we believe we had created a model of TVET that can be applied throughout Afghanistan and, we further believe, in other countries which are seeking to move with limited resources from teacher centred education to student centred education and training.
\end{abstract}

\section{Introduction}

The institutional development to which this case study relates comes from work carried out at the National Institute of Management and Administration (NIMA) in Kabul as the team of which I was part undertook the Consultancy Services for Curricular and Academic Development Activities for NIMA, World Bank Grant H352-AF, Afghanistan Skills Development Project P102573

The project ran from August 2009 - July 2011.

In outline, the essence of the project was to support the two year diploma programme development that would offer Technical and Vocational Education and Training in three faculties: Accounting Financial Management; Management and Administration; and Information \& Computer Technology. The medium of instruction was to be the English language. Additional objectives of the project were to Provide Diploma Level Labour Market Supply, Train Teachers for Other TVET Schools, Set Accreditation \& Other Standards and Assist the Institute in its Management. This case study comprises six parts and is founded on the work I carried out in my own faculty, Accounting and Financial Management:

a. Background to the project and our involvement in it

b. Phase 1: teacher centred learning

c. Phase 2: the living classroom and Bloom's Taxonomy

d. Phase 3: teacher removals and greater student centred learning

e. Phase 4: The end of the student management of NIMA and the introduction of Kabul in the Classroom

f. Phase 5: the new semester one and the future

\section{a. Background to the Project and our Involvement in it}

Figure 1 shows the timeline that follows gives an overview of the project.

\section{Institutional Profile}

Our Institutional Partner was the Ministry of Education of Afghanistan and we were physically based in the premises of NIMA. The campus comprised four Soviet built buildings that had very few advantages to recommend it. NIMA was established in 2008 by the Ministry of Education (MOE) and the first cohort of students had been recruited in a variety of ways before we arrived. Nominally, all students should successfully have completed class 12 of the Afghanistan educational system and come from all over the country; about $30 \%$ of our students were female. The mission of the MoE revolved around capacity building of the Afghanistan workforce and our project was a fundamental and critical part of the Afghanistan Skills Development Project (ASDP) 


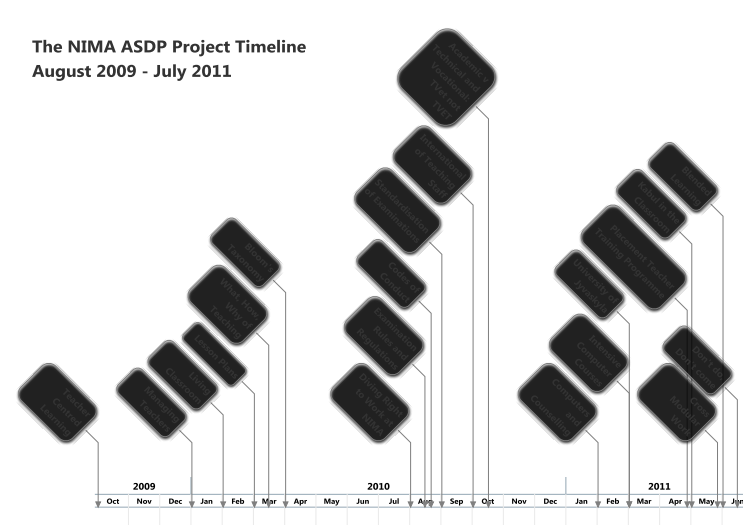

Figure 1. Project Timeline

The core of our activity was that we should provide Technical and Vocational Education and Training services so that, eg, a graduate of the faculty of which I was head, Accounting and Financial Management, should be able to take jobs in the accounting and finance function: bookkeeping, treasury duties and so on. A labour market survey had been carried out during the inception part of the project.

Effectively, 1,700 students studied at NIMA and at the end of the fourth of four semesters, almost 1,100 students graduated.

The staffing inputs provided by the project comprised 37 Junior Faculty (this is the name given to the classroom teachers), 3 Faculty Trainers (these were senior teachers whose job was contracted to be trainers in charge of the Afghan Teacher Trainee Programme), 3 Senior Faculty (each senior faculty member was de facto the head of their respective faculty), 4 Support Staff (they were all Afghan nationals and carried out a range of duties such as office manager, secretary and so on).

An important point is that semester one was started by the MoE and NIMA before our project started, meaning that all students were already in place when we arrived as was the first batch of teachers.

\section{b. Phase 1: teacher centred learning}

What I mean by Phase 1 started in the middle of October 2009 and extended to the end of December 2009.

I was appointed Senior Faculty, Accounting and Financial Management. I spent my first two weeks observing every class and every teacher that it was possible for me to observe. My major findings were that all teachers at NIMA were from Pakistan. Additional teachers were recruited by our project and during this phase all of them came from Pakistan too. Secondly, the teaching style of all teachers across all faculties was that of teacher centred learning. The majority of students were, therefore, very passive learners. I provided the teachers with direct one to one, confidential feedback. At this stage, I was concerned to begin the process of encouraging the teachers to consider moving towards a more student centred approach to their work.

We spent some time during this phase of the project revising the curriculum that we had been given to implement. My conclusions at the end of this stage of the project was that we now had a reasonable curriculum to follow and that several of the teachers were well qualified and reasonable teachers but others had clearly been recruited without regard to qualifications and talent.

\section{c. Phase 2: the living classroom and Bloom's Taxonomy}

This phase of the project relates approximately to the period early January 2010 to July 2010.

\section{Two Approaches to Managing Teachers}

I managed the teachers in my faculty in two ways: in general as an entire faculty and then in subject groupings: for example, all financial accounting teachers comprised one group. During our meetings we discussed the successes and failures of teachers' work, my observations of their work, the help and materials they needed from me, the additional materials they were developing and so on.

\section{The Living Classroom}

During this phase of the project I invented the phrase the living classroom: the need for teachers to provide something much more than the teacher centred experience that they were providing. See Appendix 1: The Living Classroom which includes the definition of what I meant by the living classroom:

The living classroom concept is nothing more than the student centred approach to teaching and learning. However, we gave it the name the living classroom because of the learning environment we found ourselves in: old, utilitarian Soviet built classrooms, linoleum floors, plain walls, no curtains or blinds and no high technology equipment. The rooms were dead!

Whilst all teachers in our Faculty were required to implement the living classroom, not everyone fully embraced the concept: again see Appendix 1. 


\section{Lesson Plans}

As we developed the concept of the living classroom, it had become obvious that the majority of teachers did not effectively plan their lessons. Faculty meetings were used to explore the concept of the lesson plan and after several meetings we developed a lesson plan template for our faculty to use. See Appendix 2: Lesson Plan Template Faculty of Accounting and Financial Management for the specimen lesson plan we developed, as at early April 2010.

\section{Bloom's Taxonomy of Educational Objectives in the Cognitive Domain and its Impact}

One of the key developments in this phase of the project was the implementation of Bloom's Taxonomy of Educational Objectives in the Cognitive Domain. Several senior members of the project team were teacher trained and/or educationists of many years' standing and we all agreed that whilst Bloom's Taxonomy is old and has been revised and alternative taxonomies developed, it is the taxonomy we should use. The significance of the implementation of a Bloom based strategy was that we were now able and encouraged to focus our thinking in a more structured way. Appendix 4: Template Examination paper: end of semester three helps to show how we used Bloom in the organisation of our teaching and learning and therefore assessment materials:

At the same time as we instituted the living classroom concept, we changed the style of the examinations. We felt able to move from Bloom's level one [knowledge] and two [comprehension] style questions to Blooms levels one, two and three [application] in the early semester quizzes, Bloom's levels one to four [analysis] in the mid term examinations and all six levels [synthesis and evaluation] of Bloom's in the end of semester examinations.

Freedom of thought and independent learning were a mystery even for some of our smartest and best students! We suffered from significant disruption during our end of semester examinations at the end of semester two. One of our tactics was to have two versions of every examination, Paper A and Paper B. We did this because the rooms available to us for all purposes were small and the number of students was large. We gave all students in one column of desks Paper A, all students in the next column of desks Paper B, all students in the column of desks after that Paper A ... this was to try to minimise cheating by copying. Table 1, below, shows how an examination room might be organized. Semester two examinations were pivotal: what we did was a massive and radical change for all students. They had never been made to sit examinations in such an organised and disciplined way: in some cases, even sitting at a desk to complete an examination was a novelty. In semester one, teachers were often threatened with violence if they failed a student. For semester two and onwards we communicated to the students and NIMA's administrators that the Academic Committee and the Examinations Committee were responsible for all results and individual teachers were not able to influence any student's results.

Table 1. Examination Room Layout

\begin{tabular}{llll}
\hline Paper A & Paper B & Paper A & Paper B \\
Paper A & Paper B & Paper A & Paper B \\
Paper A & Paper B & Paper A & Paper B \\
Paper A & Paper B & Paper A & Paper B \\
Paper A & Paper B & Paper A & Paper B \\
Paper A & Paper B & Paper A & Paper B \\
\hline
\end{tabular}

\section{Afghan Education Culture and its Effects}

In spite of all of our efforts and the development of our Academic Committee and Examinations sub Committee, we were faced with the culture of Afghan education vis a vis examination results. We knew from the reaction around Kabul that our examination systems and philosophy was widely recognised and admired: teachers and administrators came from all over Kabul to see our examination systems at work. However, students who failed examinations or who had been awarded a mark lower than they wanted all appeared at our offices with the following mantra on their lips: I am not satisfied! We adopted the Afghan law that all students were entitled to have their examination papers rechecked and that led to a major imposition on already over worked teachers. Moreover, we had students who appeared to be so desperate to succeed that they would ask for their papers to be rechecked even though they hadn't sat the examination in question!

Some of our students were violent and many were very persistent. There are two key points to make here:

1) It was NIMA's task to provide student counsellors and they did not: there were many students who needed full and unrestricted access to counselling. We provided a basic level of counselling of course but there were students with serious academic and/or personal and/or financial problems whom we could not help without the assistance of counsellors.

2) Our weakest students could not cope with the concept inherent in the living classroom 
and our other teaching/learning strategic developments. What this meant was that they believed that everything they needed to know had been said in the class and in the student handbook we prepared for them.

I had one student who had failed a tax examination who epitomised the problems faced by students who could not take responsibility for their own learning: sir, look at the examination questions and look at this handbook ... you will not see section 13 anywhere in the book. I asked him to what extent he had checked the materials himself? Had he been to any of the accounting companies in Kabul, had he been to the Ministry of Finance, had he been to see any accountants in any business to see, at any stage, whether what the teachers had said was true! The student remained silent: you might think was rather harsh but I knew this student to be otherwise an excellent, even model, student: he passed the resit!

\section{d. Phase 3: teacher removals and greater student centred learning}

Phase 3 represents the period from August 2010 to January 2011, the end of semester four.

\section{The Divine Right to work at NIMA}

The end of semester two and the beginning of semester three gave us pause for thought. We looked carefully at the way our teaching/learning strategy was developing and the response of our teachers to it: we asked ourselves; could all of the teachers in all faculties cope with the growing demands of the living classroom? We drew up a list of eight teachers whom we felt could not help us to take our strategy forward.

\section{Examination Rules and Regulations and Codes of Conduct}

We developed many of our own examination rules and regulations and we developed codes of conduct for students and a separate one for teachers. In terms of the internationalisation of NIMA, the University of Jyvaskyla, a sub contractor to this project, commented that they were standard in their style and content with universities and colleges throughout Europe. We adopted our rules and codes without fear or favour.

\section{Standardisation of Examinations}

In addition to the initiatives reflected in the preceding section, we also improved the quality of the examination experience by standardising the nature and layout of all examinations.
Standardisation took place for the first time in semester three and applied to all examinations in all faculties.

\begin{tabular}{|c|c|c|}
\hline $\begin{array}{l}\% \text { of } \\
\text { Assessment }\end{array}$ & Assessments & $\begin{array}{l}\text { Bloom's } \\
\text { Taxonomy }\end{array}$ \\
\hline 5 & $\begin{array}{l}\text { In class assessment: } \\
\text { attendance and } \\
\text { participation }\end{array}$ & $\mathrm{n} / \mathrm{a}$ \\
\hline 5 & Quizzes & $\begin{array}{l}\text { Knowledge and } \\
\text { comprehension }\end{array}$ \\
\hline 10 & Assignment & $\begin{array}{l}\text { Knowledge, } \\
\text { comprehension and } \\
\text { application }\end{array}$ \\
\hline 20 & Mid Semester Examination & $\begin{array}{l}\text { Knowledge, } \\
\text { comprehension, } \\
\text { application and } \\
\text { analysis }\end{array}$ \\
\hline 60 & $\begin{array}{l}\text { End of Semester } \\
\text { Examination }\end{array}$ & $\begin{array}{l}\text { Knowledge, } \\
\text { comprehension, } \\
\text { application, analysis, } \\
\text { synthesis and } \\
\text { evaluation }\end{array}$ \\
\hline
\end{tabular}

Again with Bloom's Taxonomy at the front of our minds, we designed the assessment schedule to reflect the progression within any given semester:

Column one of the above table shows the weighting for each assessment within the overall assessment for an entire semester. Please note that we did not agree to the $60 \%$ weighting for the end of semester examination but were told by the $\mathrm{MoE}$ and NIMA's administration that this is a legal requirement in Afghanistan. The problem here is that it is possible for a student, in theory at least, to pass their semester with a very good performance in the final examination and a weak performance throughout the semester. Such students did not exist, however!

The application of Blooms Taxonomy in this way gave a firm structure to the assessment schedules for any given semester. The taxonomy allowed teachers to develop their teaching strategies in a way that brought certainty to their work. Moreover, we then standardised the two sets of examinations held during semester three.

\begin{tabular}{ll}
\hline Mid Semester Examination & End of Semester Examination \\
\hline $\begin{array}{l}\text { Section A: multiple choice, } \\
\text { true/false, fill in the gaps }\end{array}$ & $\begin{array}{l}\text { Section A: multiple choice, } \\
\text { true/false, fill in the gaps }\end{array}$ \\
$\begin{array}{l}\text { Section B: application and } \\
\text { analysis questions }\end{array}$ & $\begin{array}{l}\text { Section B: application and } \\
\text { analysis questions }\end{array}$ \\
& $\begin{array}{l}\text { Section C: synthesis and } \\
\text { evaluation questions }\end{array}$ \\
\hline
\end{tabular}

The above schedule applied to semester three only: we felt the need to impose such a schedule otherwise it would be very difficult to defend ourselves if anyone, rightly, said to us that it is difficult to say that examination paper $\mathrm{A}$ is equivalent to examination paper B.

In semester four we changed the end of semester examinations requirement in that we felt that there should be no place in semester four for multiple 
choice etc questions. For semester four, then, the following became the requirement.

Semester Four: End of Semester Examination

Section A: application and analysis questions (knowledge and comprehension subsumed)

Section B: synthesis and evaluation questions

\section{Internationalisation of the Teaching Staff}

As we experienced difficulties with some of our teachers, we widened our net and recruited teachers from other countries. By the end of the project, we had teachers from Pakistan, India, Sri Lanka, Kyrgyzstan, Ireland and the USA; and other, non teaching, members of the project team from the USA, Australia, Canada, France.

I did discuss with the World Bank monitoring and evaluation team that it would have been better and would be better for the future if many more native speaker, suitably qualified foreign teachers be employed within any future NIMA aid project. Such an approach would attempt to ensure that knowledge and skills transfer can take place at a higher level than we were, I have to be honest, able to provide. We did a good job, it is true, but could it have gone better? The answer must be yes and the design of the NIMA project left a lot to be desired!

\section{Academic $v$ Technical and Vocational}

The implementation of a Bloom's Taxonomy centric educational regime meant that we could start the move from academic to technical and vocational teaching and learning. Our aim, then, was to implement the fundamental concepts underlying Figure 2, in which the origin is day one of a student's life at NIMA.

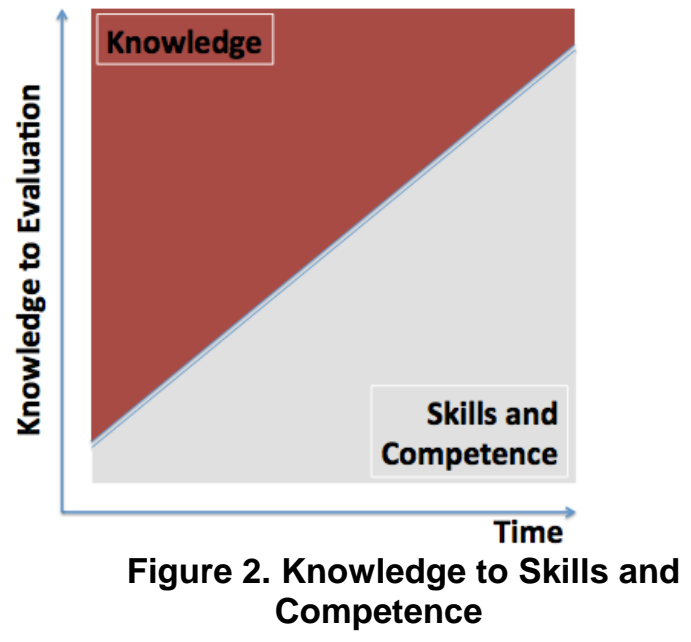

\section{e. Phase 4: The end of the Student Management of NIMA and Kabul in the Classroom}

This phase of this article represents the period from February 2011 - May 2011.

By this time in the project we were, in my opinion, well on top of everything. We had learned the way that most if not all aspects of our work should progress; we were meeting all teaching/learning milestones set out in the project and we had turned NIMA round completely in the sense that when we arrived we appreciated that the students, essentially, managed both NIMA and the Deputy Ministry of TVET. What I mean is that if students did not like something that teachers did or that we did or that administration did, they would complain. To simplify what happened, we learned that the last student to see the Director of NIMA effectively managed NIMA.

There was no management structure at NIMA: the administrators were afraid of the students because they knew that the students had free access to the Deputy Minister in charge of TVET and some students had direct access to the Minister of Education himself. Moreover, because the Minister and Deputy Minister were afraid of members of Parliament, a vicious circle of paranoia ran around the MoE and therefore NIMA: the student knew how to exploit this weakness.

Our position was that we had been given a clear mandate to set up an international style and standard TVET college and that's what we did. We rightly took the view that if anyone had a difficulty with the way we felt we had to work, they must resolve them themselves. That's not to say that we didn't compromise, we did. We spent a lot of the time from January 2010 - August 2010 working closely with the Director of NIMA and the Deputy Minister of TVET. We did things we didn't like and we did things that they didn't like. Eventually, however, we had to make it clear that when a student failed, threatening letters from those in authority meant nothing to us. We made it clear that our academic committee and examinations sub committee contained all of the procedures needed to manage the students and threats to summon a commission of enquiry from the DM TVET again meant nothing and was not the way to manage NIMA.

This aspect of our work was absolutely core to the successes and failures we might have had. However, my aim in writing this paper is to set out the positive aspects of our work. Consequently, I am content to flag the problems discussed here but not to dwell on them. 


\section{Computers and Counselling}

It is a matter of fact that NIMA's administration not only became more and more difficult to work with but they refused to provide the infrastructure we needed to do our work effectively. For example, can you imagine a TVET school or college without any of the following?

- Library

- Computer laboratories

- Student counsellors

- Placement officers

Again, I will not explore these matters in this article because I want to emphasise the positive work we did; but here is one example of the implications of this list that reflects some of the pressures of working at NIMA.

On the final day of semester four there was a hand over ceremony in which the Deputy Minister of TVET came to NIMA and officially opened a newly developed suite of computer rooms. The practicality of this was that none of our students, apart from the ICT students, had had access to a computer at NIMA. This meant that any efforts at teaching modern bookkeeping systems, database management systems, spreadsheeting, communications via word processing had been impossible for us and these software packages had, therefore, all remained mysteries for the many students at NIMA who had never had access to and used a computer.

\section{Computer Intensive Courses}

Teaching finished now for a while and we took the opportunity to run intensive courses in Bookkeeping and other software. Remembering that there were around 1,500 students eligible for this training and only a month in which to do it, this was a major challenge for our teachers and students but everyone who wanted to be trained was trained. This was a stop gap programme but we feel it was worth it.

\section{Placement Teacher Training Programme}

In a sense it was an aside but one of the most important initiatives we took at NIMA was the Placement Teacher Training Programme. Lyn Bowers and I devised and developed this programme: Lyn and I spearheaded the implementation of the programme too but then many of our junior faculty also became involved in it.

The underlying philosophy of the PTT was simple: NIMA was unique in Afghanistan and if there are to be further attempts at replicating the success of NIMA across Kabul and then
Afghanistan, Afghanistan needs a cadre of teachers and administrators who know what to do! Consequently, we wanted to begin the training of potential teachers for the future of NIMA and TVET throughout the country.

We made it very clear in the interview stage of the recruitment process that the PTT programme could not lead directly to a job on completion, that it was a placement/internship programme like all other placement programmes. Nevertheless, we encouraged NIMA and the DM TVET as well as the World Bank to reflect on this programme and consider our objectives for the future for it.

Suffice it to say that some of the work done in this programme was exceptional: the students we selected were already disciplined and reacted to the opportunity to come to know their "distant and strict" foreign faculty in a completely different way. The students appreciated that the foreigners were dedicated, caring teachers whose knowledge and teaching skills were by far the best they had ever seen: forgive my lack of modesty here!

\section{6. $\quad \mathrm{TV}_{\mathrm{e}} \mathrm{T}$ not TVET}

As we prepared for the second cohort of students we were able to address a number of strategic teaching and learning issues, so the ideas discussed above could be implemented in full. In the various faculty meetings and strategy development papers that we shared, I introduced the concept of TVeT rather than TVET. We needed our teachers to stress the TV\&T and deemphasise the E: the concept of the living classroom and its development would now require much more emphasis on TV\&T and much less on $\mathrm{E}$ !

\section{Kabul in the Classroom}

I suppose the epitome of the shift from tvEt/TVeT to TVET is what we called the Kabul in the Classroom approach. What we did here was to tell our teachers that in order to move away from $\boldsymbol{E}$ to $\boldsymbol{e}$ we had to convince the students that what they were learning was applicable and very practical: that is, whilst we prepare teaching materials for them, those materials drive the student out of the classroom and into the community and businesses to test and check their learning as much as possible.

In my faculty we had meetings in which we discussed the up and coming semester and in open session rather than subject group, we explained how we would, for example, explain the need for and usefulness of accounting information; we discussed how to use set theory in statistics in an introductory and practical setting; we even discussed how to go and find real live economics in the community and how to apply it. 
These discussions then became enshrined in the teaching materials as we prepared materials along the following lines:

- Section 1: introduction, background and theory

- Section 2: development and examples

- Section 3: case exercises and case studies including Kabul in the classroom cases in which the students are given tasks that can only be completed by interacting indirectly and directly with the community

- Section 4: homework ...

- Section 5: classroom presentations: all students MUST make at least one presentation of $5-10$ minutes in every subject on a $2-3$ week cycle

The specimen materials we prepared for our teachers were inspired by a training session with our group of Afghan Teacher Trainees (qv): I asked each of the trainees to prepare a case study that they could use in semester one with our new cohort of students. The brief was simple: choose something that will help you to introduce, for example, bookkeeping and accounting, economics and so on. We had good examples to choose from including the making of wheelbarrows that one can see almost all over Kabul.

The example that really took my eye was the making of potato crisps. Instantly, I appreciated that this example can be used in a simple setting as well as a much more complex setting. For example, we worked on making crisps at home: kitchen, cooker, pan, oil, potatoes ... we then discussed how to begin working on a larger and larger scale. Then I asked the students to go and take a look at the crisps that are on sale in the shops and supermarkets around Kabul and I took in a large bag of Afghanistan made crisps for us all to share and discuss.

We developed this case over several sessions and I shared this case with our full time teachers, from all faculties. I did not expect that all teachers would produce such comprehensive cases for every topic but that was not the point: they were required to read and emulate them.

\section{Cross Modular Work}

By cross modular I mean that a case has to consider a variety of aspects of accounting, economics and other subjects/topics and not just accounting or economics:

This file is just an introduction to the cross modular aspects of the potato crisps making case study. The tasks, therefore, have to be expanded to ensure that all subjects are catered for in the cross modular setting.

Cross modularisation of teaching and learning was another new concept for all of the teachers at NIMA but we made it mandatory for them to consider it as they developed their materials, lesson plans and so on.

We felt that cross modularisation was a perfect accompaniment to the concept of Kabul in the Classroom.

Please note, we were well aware that cross modularisation can take a great deal of time and effort to implement and apply in full: we compromised and said that each topic should be related to English language teaching/learning and one other subject, with the proviso that, apart from English, the other topic chosen cannot be the same topic after topic or subject after subject.

\section{The Motivation for Cross Modular Work}

Having worked in the traditional teacher centred way and then working our way through the living classroom concept, we appreciated that whilst many of our students were speaking and using the English language with more and more ability and confidence, they were studying their subjects in isolation from each other, as suggested by Figure 3, below:

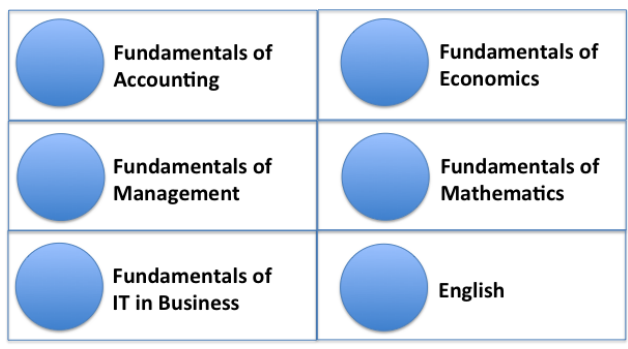

Figure 3 Prior Curriculum

Figure 4, below, shows the new approach that stemmed from cross modularisation; we put English at the very centre of everything and we also realised that we had taken ourselves to the idea of blended learning. 


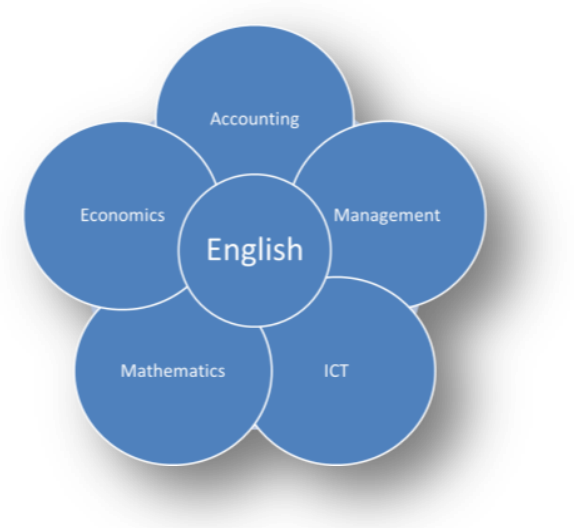

Figure 4. From Knowledge to Synthesis

\section{Blended Learning}

By blended learning we meant that all topics and subjects should be taught with a variety of approaches to teaching and learning in mind.

From then on all teachers, all subjects and all topics were developed and prepared with blended learning in mind. As an example, the potato crisp case study illustrates the blended learning concept quite well:

- A physical product or service ... much better if it is something relevant to the situation you are in. For example, don't investigate McDonald's in Kabul or Tesco in Yerevan if these businesses are not represented there.

- A video/film to watch as part of the process

- General class discussions

- Student group work

- Kabul in the classroom as students are sent to make/find examples of potato crisps

- Numerical calculations: with or without the use of a spreadsheet

- Word processing of solutions by students

- Computer based presentations by students

A search of the internet will reveal a wide range of resources relating to blended learning and we are aware that there is an equally wide range of definitions of it and of its efficacy. Our opinion was that in order to make NIMA more in tune with the international community we needed to work on, develop and implement these more modern approaches to education than teacher centred learning.

\section{Don't do, Don't Come}

Finally in this section, we created the mantra of don't do, don't come. Whilst we made a lot of progress in developing the teaching and learning strategies for NIMA, we did so in peace at times but we also met criticism and resistance at other times. What we felt the need to do was make it quite clear that the new semester would be a brand new beginning. That is, that from day one of the new semester, we would instill a sense of discipline and order and organisation that was not always evident in the NIMA that we inherited and that I have described above.

Consequently, don't do, don't come was the message that said, if you don't like what we do and you don't like the way that we do it, then please stay away.

Again this sounds harsh but we wanted to leave a legacy for NIMA and Afghanistan that really would stand out and that really would be long lasting. We were keen to leave a long lasting legacy of as near to excellence as possible.

\section{f. Phase 5: the new semester one and the future}

This phase of this article represents the period from June 2011 - July 2011. Because our project came to an end on $11^{\text {th }}$ July 2011 , we were not able to implement for more than half a semester the don't do, don't come policy, Kabul in the classroom and blended learning. Part of the don't do, don't come policy was respect for teachers, administrators and each other. It is a fact of life that Afghanistan is still a tribal society and people from different regions have different cultures and norms and they sometimes led to tensions in the classroom and on campus. We set standards for the new cohort and stuck to them. See more on this topic in case study two in this series: NIMA: working with the Afghan Counterparts.

\section{Conclusions}

This project was one of the most fascinating project and assignments I have ever worked on. The task was something I had done before so I was relishing the chance to try out the successful things that I had done before. I achieved many of these objectives and dreams.

Everything I have reported here is the reality of what happened as I saw it. It should be clear from my words and from the appendices that we made very good progress in many aspects of our work. I have not reported absolutely everything we did, so there are some things that have been left unsaid. For example, there is much more that I could have said on the examinations processes and on the development and implementation of the academic committee.

Nevertheless, it was a privilege to work in Afghanistan and I learned so much about Afghanistan students and administrators as well as 
many aspects of the work of the Deputy Ministry TVET within the Ministry of Education. But it must be said that the biggest battle we had and therefore the largest obstacle we faced was the intransigence of NIMA's administration. For the entire first four semesters of the work of NIMA there were no computers, there was no library, there were no student counsellors and the placement officers who were eventually recruited were of such low quality that they were not helpful to us.

At the time of writing I still receive messages of friendship, gratitude and support from former students and colleagues at NIMA and that is very comforting.

My last word has to be, however, that in order for us to achieve what we achieved, we needed to be very single minded in the ways in which we reacted to and worked with our Afghanistan counterparts. It was not easy and at times it seemed as if absolutely everyone in Afghanistan was working against us. Again, I will write more about this in case study two in this series: NIMA: working with the Afghan Counterparts.

Let me give the very last words in this article to my former colleague and Team Leader on this project, Charles Giammona:

\section{Summary}

- "In this project, the boat is being built and sailed at the same time."

- All large projects have start up and growing pains.

- Twenty years from now, Afghanistan will have a sustainable middle class workforce because of the vision and dedication of the pioneer faculty, staff and students on this project.

- Do not become distracted from the long term goal by petty and/or self serving interests, or by those who do not understand the commitment required for success a generation away. 